\title{
Paolo Guidetti \\ Consumers of sea urchins, Paracentrotus lividus and Arbacia lixula, in shallow Mediterranean rocky reefs
}

Received: 18 September 2003 / Revised: 22 March 2004 / Accepted: 22 March 2004 / Published online: 8 May 2004 (C) Springer-Verlag and AWI 2004

\begin{abstract}
Underwater observations on fish and asteroid consumers (i.e. predators and scavengers) of sea urchins, Paracentrotus lividus and Arbacia lixula, were carried out at several locations in shallow Mediterranean rocky reefs. Observations conducted in the marine reserve of Torre Guaceto (Adriatic Sea) revealed that sparid fishes, Diplodus sargus and D. vulgaris, are the main fish predators of small $(<1 \mathrm{~cm}$ in test diameter) and medium (1$4 \mathrm{~cm}$ ) sea urchins, whereas the labrids Coris julis and Thalassoma pavo preyed only upon small sea urchins. Large D. sargus were able to prey upon small and medium, and occasionally large $(>4 \mathrm{~cm})$ sea urchins, whereas medium and small Diplodus preyed mainly upon small sea urchins. The number of sea urchins preyed upon by fishes was negatively related to sea urchin size for both species. P. lividus appeared to be subject to higher predation levels than A. lixula. The scavenger guild comprised 11 fish species, with $D$. sargus, D. vulgaris, Coris julis and Chromis chromis accounting for about $80 \%$ of scavenger fishes. Observations performed at several locations in the Mediterranean on the predatory asteroid Marthasterias glacialis revealed that only $3 \%$ of the detected individuals were preying upon sea urchins. Due to the importance of sea urchins for assemblage structure and functioning of Mediterranean rocky reef ecosystems, these results may have also important implications for management of fishing activities.
\end{abstract}

Keywords Sea urchins - Predators - Scavengers · Rocky reefs $\cdot$ Mediterranean Sea

Communicated by H.-D. Franke

P. Guidetti ( $)$

Laboratorio di Zoologia e Biologia Marina, DiSTeBA, CoNISMa, Università di Lecce,

via Provle Monteroni, 73100 Lecce, Italy

e-mail: paolo.guidetti@unile.it

Tel.: +39-0832-298-935

Fax: +39-0832-298626

\section{Introduction}

It is well known that predation is one of the most important biological processes affecting community structure and ecosystem functioning (Hairston et al. 1960; Duffy and Hay 2001, and references therein). Besides direct effects on their preys, predators may also influence community structure indirectly whenever their prey species strongly interact with other species of the community (Power 1992). The effects of predators, therefore, may extend well beyond the prey consumed throughout the so-called "trophic cascades" (Paine 1980; Witman and Dayton 2001).

In shallow sublittoral rocky reefs in the Mediterranean Sea, as seen in other temperate regions (Andrew and Underwood 1993; Tegner et al. 1995; Scheibling 1996, and references therein), sea urchins (Paracentrotus lividus and Arbacia lixula) may strongly influence marine benthic communities, in some cases driving the transition from erect macroalgal assemblages to coralline barrens (Sala et al. 1998, and references therein; Guidetti et al. 2003). Abundance, size structure, and feeding behavior of sea urchins may be influenced by predation (Duggins 1980; Tegner and Dayton 1981; McClanahan and Shafir 1990; Sala and Zabala 1996; Scheibling 1996; Guidetti et al. 2003), which stresses the potentially great functional importance of consumers of echinoids in the control of sea urchin populations and, furthermore, the structure of entire communities associated with rocky substrates.

Potential predators of sea urchins in Mediterranean sublittoral rocky habitats encompass large crustaceans (Eriphia spinifrons, Maja squinado, Palinurus elephas), asteroids (Marthasterias glacialis) and fishes (e.g. Diplodus spp., Coris julis) (Sala et al. 1998, and references therein). There is no clear scientific evidence, however, that $E$. spinifrons and $M$. squinado are important predators of sea urchins in shallow rocky reefs (Sala et al. 1998). As regards the spiny lobster, $P$. elephas, it has to be considered that this crustacean usually lives in deeper habitats than the shallow rocky reefs where $P$. lividus and $A$. lixula thrive (Boudouresque and Verlaque 2001). Al- 
though Goñi et al. (2001) reported that 'echinoidea' can be found in the stomachs of spiny lobsters, the lack of spatial overlap leads to the conclusion that spiny lobsters are not involved in the control of sea urchin populations in shallow rocky reefs. The starfish M. glacialis was reported feeding upon P. lividus in Posidonia oceanica seagrass beds by Dance and Savy (1987 a), who estimated that about $10 \%$ of adult sea urchins might annually be removed by starfish predation. In their cage experiments, however, these authors removed any alternative prey, and thus probably overestimated predation rates of M. glacialis upon sea urchins. Although Fanelli et al. (1999) reported negative correlations between $M$. glacialis and sea urchin density in shallow rocky reefs in SE Italy, there is no clear evidence so far to show that this starfish is an efficient sea urchin predator in the field. Fishes have been reported by many authors as the most important and diverse guild of sea urchin consumers in the Mediterranean Sea (Sala 1997, and references therein). Although a great number of fish species have been indicated as potential sea urchin consumers (that includes predators and scavengers), recent studies have provided evidence that only a few fish, which may be grouped into two main guilds, are actually important as predators: (1) predators of adult and juvenile sea urchins (chiefly D. sargus and D. vulgaris); and (2) predators of juvenile sea urchins only (e.g. Coris julis). Both these guilds include several fish species of economic importance (mainly the two Diplodus spp.; Harmelin et al. 1995). A decrease in their abundance (e.g. due to fishing) may have consequences on their prey (i.e. sea urchins) and, in the end, on the entire benthic community in shallow rocky reefs. Many fish species among those that are known as consumers, conversely, are actually scavengers (Sala 1997), but these latter obviously cannot control sea urchin populations.

The present knowledge about sea urchin consumers in the Mediterranean, however, is still fairly scanty and spatially limited to a few areas in the basin (Sala 1997). This stresses the need to widen the spatial scale of observations in order to look for general patterns. Furthermore, in situ observations allowing quantification of the importance of a species as predator or scavenger (McClanahan 1995; Sala 1997) have referred exclusively to $P$. lividus. No data are available about consumers of $A$. lixula, which co-occurs with $P$. lividus in shallow rocky reefs, and in some case shows higher density and/or biomass, vmainly in the southern sectors of the Mediterranean (Guidetti et al. 2003, 2004).

This paper aims to provide information about predators and scavengers of the sea urchins P. lividus and A. lixula in shallow Mediterranean rocky reefs.

\section{Methods}

Observations on fish consumers

Observations on fish predators and scavengers were made by means of SCUBA diving within the marine protected area (MPA) of

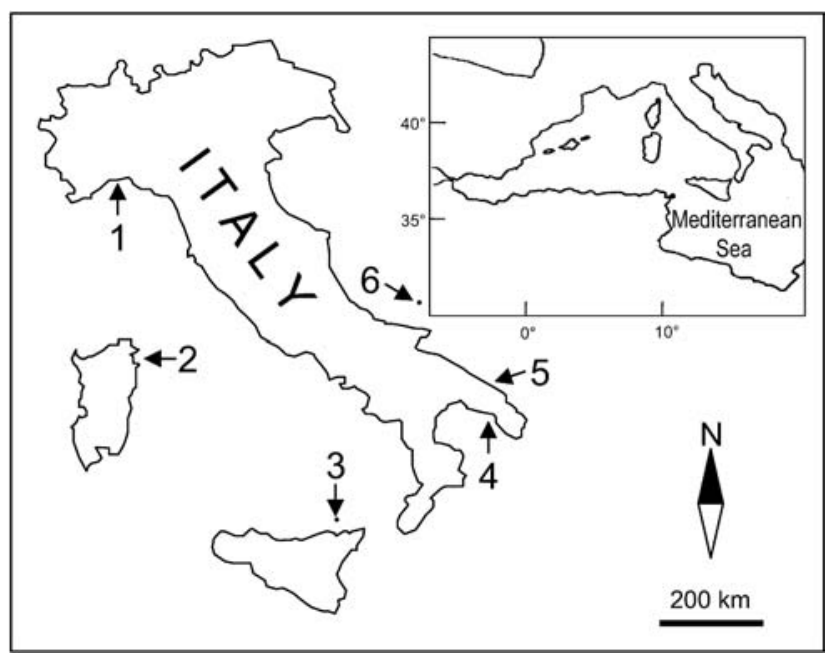

Fig. 1 Study locations along the coast of Italy. 1 Arenzano; 2 Olbia; 3 Lipari Island; 4 Porto Cesareo; 5 Torre Guaceto; 6 Tremiti Islands

Torre Guaceto (southern Adriatic Sea; Fig. 1) from May 2002 to July 2003. The whole reserve, established in 1992, covers about 2,220 ha, and the two no-take zones cover about 180 ha. This MPA is successfully enforced, and observations were made inside the two no-take zones since predation by fish was expected to be far greater here, and thus easier to observe, than in fished areas.

Sea urchins, i.e. P. lividus and A. lixula, were collected by SCUBA diving in areas outside the reserve (inside they show very small densities; unpublished data), taking care to avoid any damage to spines. A total of 300 sea urchins (150 P. lividus and $150 \mathrm{~A}$. lixula) were collected, measured with a calliper and assigned to three size categories: small (test diameter without spines less than $1 \mathrm{~cm} ; n=50$ for each species), medium (from 1 to about $3.5 \mathrm{~cm}$; $n=50$ ) and large (more than $3.5 \mathrm{~cm} ; n=50)$. Sea urchins were positioned (with the oral side on the substratum) in five groups of five specimens each over rocky substrate at about 4-7 m depth within the two no-take zones of the Torre Guaceto MPA. The observer, hidden behind a boulder at a distance of about 5-10 m (depending on water clarity) from the baited sites, noted for approximately 15 min the number of sea urchins preyed upon, and the species and number of 'consumer' fishes, assigning them to one of two guilds: (1) predator guild (i.e. species able to open sea urchins by breaking the tests); (2) scavenger guild (i.e. species feeding upon already opened sea urchins). The size of predatory fishes was evaluated by using three size categories (i.e. small, medium and large) on the basis of the maximum total length reached by each species (Fischer et al. 1987).

As predatory fishes usually become aggressive after having broken a sea urchin, which may keep away other fish (i.e. scavengers) (Sala 1997), sea urchins of both species which had already been opened by the observer were also offered to get a more exhaustive list of scavenger fishes.

Observations on starfish predation

Underwater observations on predatory patterns of the starfish $M$. glacialis were made in shallow rocky reefs $(2-10 \mathrm{~m}$ depth) by means of SCUBA diving from June 2001 to July 2003 in several areas of the Mediterranean basin (Fig. 1): Arenzano (Ligurian Sea); Olbia (Sardinia Island, central Tyrrhenian Sea); Lipari Island (southern Tyrrhenian Sea); Porto Cesareo (Ionian Sea); Torre Guaceto (southern Adriatic Sea); and Tremiti Archipelago (central Adriatic Sea). Each starfish detected was turned upside down to check whether it was (1) feeding on a sea urchin or other prey, (2) 
moving, or (3) inactive (immobile but not feeding). Whenever a sea urchin was observed to be preyed upon by a starfish, its species, size (test diameter without spines), and position relative to that of the predator were recorded.

\section{Results}

\section{Fish consumers}

Eighteen fish species were observed to consume sea urchins at the MPA of Torre Guaceto. All 18 fish species consumed P. lividus, whereas only 14 of them consumed A. lixula (Table 1). Four species were observed to be successful as predators of sea urchins: D. sargus, D. vulgaris, Coris julis and T. pavo, and their relative importance varied depending on species and size of sea urchins (Fig. 2).

A total of $37(24.7 \%)$ out of the 150 P. lividus offered to predatory fishes were actually eaten. The number of sea urchins preyed upon by fishes was highest (24 out of 50) for small-sized, intermediate (12 out of 50) for mediumsized, and smallest (1 out of 50) for large-sized P. lividus (Fig. 2). Small-sized P. lividus were preyed to nearly the same extent by the two Diplodus species and Coris julis, and to a lesser extent by $T$. pavo. D. sargus was the most important predator of medium-sized $P$. lividus, followed by $D$. vulgaris, whereas a single large-sized $P$. lividus was preyed upon by $D$. sargus.

The total number of individuals of $A$. lixula preyed upon by fishes $(13$, i.e. $8.7 \%$, out of 150$)$ was lower than

Table 1 Fish species observed to consume sea urchins ( $P$ predators; $S$ scavengers) (Paracentrotus lividus and Arbacia lixula) in the no-take zones of the MPA of Torre Guaceto

\begin{tabular}{|c|c|c|c|c|}
\hline Family & & & A. & \\
\hline Species & $\mathrm{P}$ & $\mathrm{S}$ & $\mathrm{P}$ & $\mathrm{S}$ \\
\hline $\begin{array}{l}\text { Blenniidae } \\
\text { Parablennius gattorugine } \\
\text { P. rouxi } \\
\text { Gobiidae } \\
\text { Gobius bucchichii } \\
\text { Labridae } \\
\text { Coris julis } \\
\text { Symphodus doderleini } \\
\text { S. mediterraneus } \\
\text { S. ocellatus } \\
\text { S. roissali } \\
\text { S. rostratus } \\
\text { S. tinca } \\
\text { Thalassoma pavo } \\
\text { Pomacentridae } \\
\text { Chromis chromis } \\
\text { Serranidae } \\
\text { Serranus cabrilla } \\
\text { S. scriba } \\
\text { Sparidae } \\
\text { Diplodus annularis } \\
\text { D. sargus } \\
\text { D. vulgaris } \\
\text { Oblada melanura }\end{array}$ & $\stackrel{0}{0}$ & $\begin{array}{l}0 \\
0 \\
0 \\
0 \\
0 \\
0 \\
0 \\
0\end{array}$ & ? & ○ \\
\hline
\end{tabular}

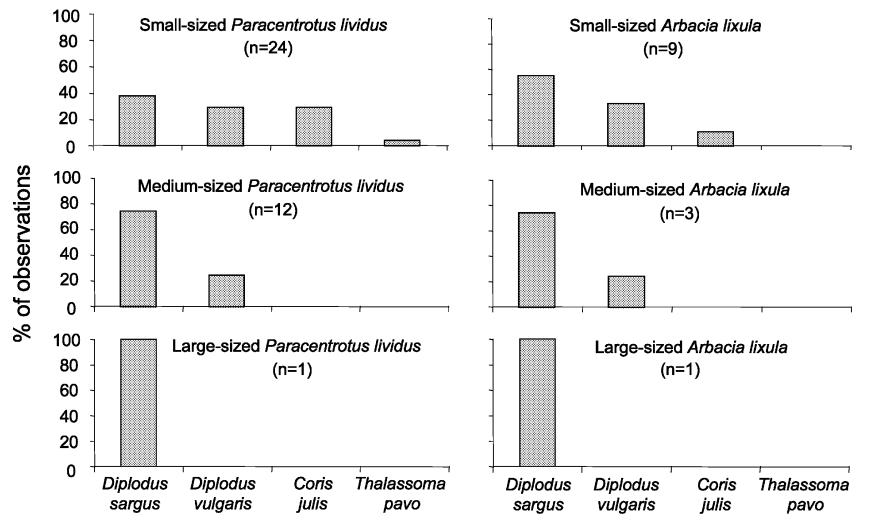

Fig. 2 Fish species (predator guild) observed to successfully attack sea urchins (Paracentrotus lividus and Arbacia lixula) of different sizes

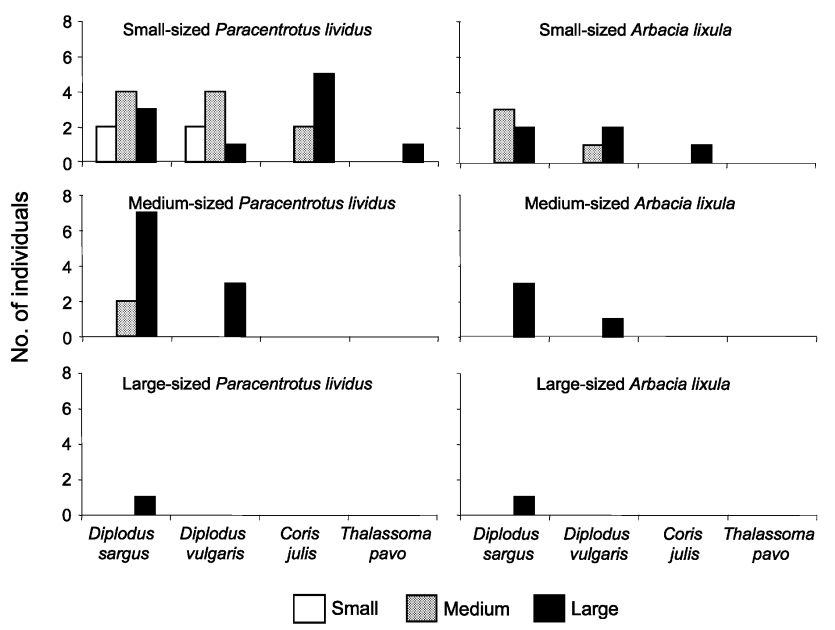

Fig. 3 Size category and number of individuals of predatory fish species observed preying upon sea urchins ( $P$. lividus and A. lixula) of different sizes

that of $P$. lividus and, similarly to the other sea urchin, predation by fish decreased with increasing sea urchin size. Overall, nine small-sized, seven medium-sized, and one large-sized A. lixula (out of 50 of each size category) were successfully preyed upon (Fig. 2). D. sargus was observed to be the most relevant predator of this sea urchin. Small-sized A. lixula were mostly preyed upon by D. sargus, followed by D. vulgaris and Coris julis. Medium-sized $A$. lixula were successfully attacked by $D$. sargus, and to a lesser extent by D. vulgaris, whereas only $D$. sargus was observed to break a large specimen of $A$. lixula in one case (Fig. 2).

The success of the above predatory fishes in breaking sea urchin tests was related to predator size (Fig. 3). Small sea urchins were eaten by small Diplodus, but also by medium- and large-sized specimens of all four predatory fishes. Most medium- and large-sized sea urchins, however, were successfully preyed upon by large $D$. sargus individuals and, to a lesser extent, $D$. vulgaris. Only very large D. sargus (around $40 \mathrm{~cm}$ TL) were observed to bite 


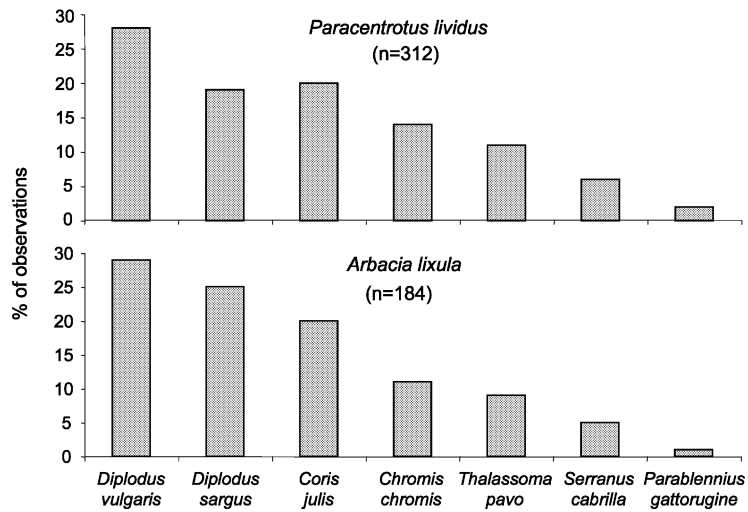

Fig. 4 Fish species (scavenger guild) observed to eat carcasses of the sea urchins $P$. lividus and $A$. lixula

and break sea urchins larger than $3.5 \mathrm{~cm}$ in diameter (Fig. 3).

Six species of scavenger fishes were observed feeding upon carcasses of $P$. lividus and A. lixula previously broken by predatory fishes. D. vulgaris was the most frequent scavenger, followed by Coris julis and D. sargus, and with decreasing importance by Chromis chromis, $T$. pavo, Serranus cabrilla and Parablennius gattorugine. In particular, Chromis chromis individuals were observed eating small sea urchin fragments floating in the water at a short distance $(10-20 \mathrm{~cm})$ from the carcasses where all species usually crowded. The species composition of the scavenger guild was similar for the two species of sea urchins (Fig. 4).

The list of fish species potentially acting as scavengers of sea urchins, however, includes species not directly observed to eat sea urchins broken by predatory fishes. On the whole, I observed 18 fish species eating alreadyopened $P$. lividus, and 14 species biting already-opened $A$. lixula. It is worth noting that all species observed to prey upon sea urchins were also active as scavengers (Table 1).

\section{Starfish predation}

A total of $132 \mathrm{M}$. glacialis individuals were detected at the six investigated locations over the two years of study. Due to the comparatively low number of observations at each location (the starfish showed very low density everywhere), data were pooled to provide an overall picture of the predatory activity of $M$. glacialis in shallow rocky reefs (Fig. 5). Less than $10 \%$ of the detected individuals were inactive, which suggests that this starfish is also an active predator during daytime. About $27 \%$ of starfishes were foraging for prey (e.g. when offered prey such as medium-sized gastropods, Hexaplex trunculus, they promptly assumed the typical predatory behaviour). Most of the starfishes (about 35\%) were observed to prey upon the rock-boring mollusc Lithophaga lithophaga (date mussel), whose valves are kept open by the starfish podia, while the prey is digested inside its hole by the everted stomach of M. glacialis. Mollusc gastropods,

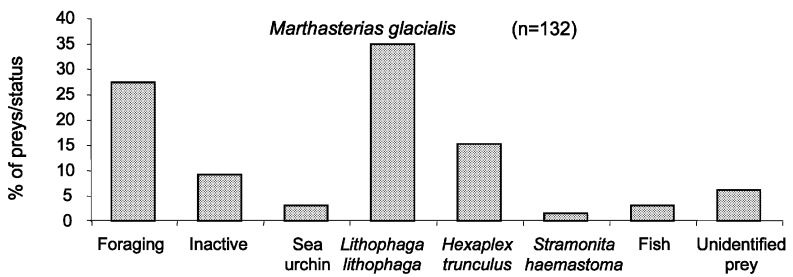

Fig. 5 Frequency of prey items of the starfish Marthasterias glacialis over rocky substrates

namely $H$. trunculus and Stramonita haemastoma (in a single case) constituted about $17 \%$ of the prey of $M$. glacialis, whereas about $6 \%$ of the starfishes were found eating 'unidentified prey' (i.e. the starfish's stomach was everted inside a small crevice but the prey was not identifiable). Four specimens (3\%) of M. glacialis were found to eat small fishes, probably acting as scavengers. Finally, another four M. glacialis specimens (3\%) were found preying on $P$. lividus ranging in size (test diameter) from 2.8 to $3.5 \mathrm{~cm}$. They were digested by the everted stomach of the starfish, after the sea urchins had been turned upside down.

\section{Discussion}

The results of the present study provide evidence that many fish species consume sea urchins, i.e. P. lividus and A. lixula, in shallow Mediterranean rocky habitats, while only a few species actually prey upon them by breaking their tests. Predation, in addition, appears to be dependent on both prey and predator size, and was found to be greater on P. lividus than on A. lixula.

The most relevant fish predators of sea urchins are $D$. sargus and D. vulgaris. D. sargus, in particular, has been observed to prey upon small, medium and large specimens of both sea urchin species. However, only very large D. sargus (around $40 \mathrm{~cm}$ TL) are able to open sea urchins larger than $4 \mathrm{~cm}$ in test diameter, while $D$. sargus of any size prey upon small sea urchins. In contrast, the labrids Coris julis and, to a lesser extent, T. pavo, prey only on small sea urchins. These results substantially agree with the observations from other marine reserves in the western Mediterranean: D. sargus has been reported as the main predator of sea urchins in Medes (Spain) and Scandola (Corsica, France) where the role of T. pavo was negligible, whereas in Cabrera (Spain) D. sargus was found to be functionally replaced by $D$. vulgaris, and $T$. pavo represented an important predator of juvenile $P$. lividus (Sala 1997). The relative importance of the two Diplodus species and the two labrids as predators thus seems to vary among the marine reserves considered, probably due to the actual density that these species achieve locally. Inside the MPA of Torre Guaceto, $D$. sargus is slightly more common than $D$. vulgaris (especially large individuals), and Coris julis is far more abundant than T. pavo, which could explain their different 
relative importance as consumers of sea urchins over a local scale.

Predation rates on $P$. lividus and A. lixula appear to be negatively related to sea urchin size (Sala 1997; present study). Many authors have reported that the more sea urchins are susceptible to predation, the more they tend to shelter (Guidetti et al. 2003, and references therein). Large $P$. lividus individuals $(>4-5 \mathrm{~cm})$ are often found outside shelters, whereas most smaller individuals are found in shelters (Sala and Zabala 1996). This suggests that $P$. lividus may escape fish predation after having achieved approximately $4 \mathrm{~cm}$ in test diameter. Specimens of A. lixula, in contrast, can be observed in open areas of sublittoral rocky substrates even with $2.5-3 \mathrm{~cm}$ diameter (unpublished data). This suggests that A. lixula may escape predation at a smaller size and may be subject to lower predation rates than $P$. lividus. Reasons for this may be: differences between the two sea urchins in palatability, test robustness, and/or effectiveness of protective structures (e.g. length and/or robustness of spines) (see also Tegner and Dayton 1981). Fish predation could thus affect density and cryptic behaviour of the two co-occurring echinoids differently, depending on their specific strategies to encounter fish predation. Differences in cryptic behaviour and susceptibility to predation among cooccurring sea urchin species have also been observed elsewhere (e.g. for the two genera Diadema and Echinometra), and have been hypothesised to reduce niche overlap (McClanahan 1999). This involves potential (and in some case unexpected) repercussions on the structure of the benthic macroalgal assemblages grazed by sea urchins (McClanahan 1999; Guidetti et al. 2004).

The pool of fish species acting as scavengers was much richer than the predatory guild, with the scavenger guild including all four species that have been directly observed to prey upon sea urchins. Similar findings have been reported for both tropical and temperate seas by McClanahan (1995, 1999) and Sala (1997). From this perspective, in situ underwater observations can provide a proper understanding of these relationships, while analyses of gut contents do not allow scavengers to be distinguished from predators.

The method used in this study to observe fish predation potentially suffers from some sources of bias. Observations were only conducted during daytime, only on exposed sea urchins, and in the presence of a diver-observer. Although there is evidence that predatory fishes of sea urchins in the Mediterranean Sea are mainly active during daytime (Savy 1987a), it cannot be excluded that patterns and intensity of predation may be different during night-time when, for example, $P$. lividus tends to move out of shelters (Shepherd and Boudouresque 1979). Sea urchins, in addition, were offered outside their natural shelters, which could have led to an overestimation of predation since exposed sea urchins are more susceptible. The method used in the present study may thus allow the determination of potential predators, but might be less effective in determining the actual relative frequency of predators under the natural condition of shel- tered sea urchins. Finally, it cannot be excluded that the presence of the observer using SCUBA may have biased the observations, considering that there are fishes, such as Sparus aurata, which have been reported to prey upon P. lividus (Savy 1987a; personal observation), but are much more shy in the presence of divers than the species I have directly observed preying on sea urchins.

Previous papers have reported that the starfish $M$. glacialis is a predominantly nocturnal predator (Dance and Savy 1987; Savy 1987a), although Savy (1987b) noted that this starfish may also be active during daytime. Most of the individuals I detected during daytime were found feeding, or foraging for prey. Only in a few cases were starfishes observed to prey upon sea urchins (as observed outside the Mediterranean; see Verling et al. 2003), specifically upon medium-sized $P$. lividus. The fact that many starfishes were found feeding suggests, on the one hand, that the observations may reliably represent prey preferences of the starfish, but on the other hand it cannot be excluded that predation patterns during nighttime are different from those observed during daylight. However, the findings that $M$. glacialis is usually at very low densities everywhere, and that it preys only occasionally upon sea urchins in the field, suggest that this starfish is probably unable to control sea urchin populations (see also Boudouresque and Verlaque 2001). In some areas of the southeastern Italian rocky coast, where predatory fish densities are low due to overfishing, the density of $M$. glacialis persists at a very low level, while sea urchins may reach densities of about 30 individuals $\mathrm{m}^{-2}$ (Guidetti et al. 2003). This agrees with data from other regions of the Mediterranean, and elsewhere, where predation rates by invertebrate predators of sea urchins such as large gastropods and starfishes are generally very low, even where overfishing has caused a decline in predatory fish stocks (McClanahan and Muthiga 1989; Sala and Zabala 1996).

Many points raised by the present study may have implications for management policies of Mediterranean littoral ecosystems. For many areas of the basin, there is a diffuse concern that the increasing sea urchin populations may cause an enlargement of barren grounds in rocky littoral ecosystems (see Guidetti et al. 2003, and references therein). There is increasing evidence that predation by fish exerts an important role in the dynamics of sea urchin populations (Scheibling 1996; Sala et al. 1998). D. sargus and D. vulgaris are among the most important coastal fish species from a commercial point of view, and are targeted by many kinds of fishery (e.g. spearfishing, trammel nets, angling), whereas Coris julis, chiefly large individuals, is mainly affected by angling (Harmelin et al. 1995). T. pavo is chiefly distributed in the southern parts of the Mediterranean, although it is currently spreading northwards (Guidetti et al. 2002). Its importance thus depends on the considered location, and although there are no data about the possible effects of fishing on this species, it may be affected by angling just as Coris julis is, considering that the two labrids have similar size and general habits. Several studies have 
demonstrated that densities of predatory fishes tend to be negatively related to sea urchin densities (McClanahan 1999; Guidetti and Sala, in preparation), and that predatory fish size is positively related to the success of predatory attacks (Sala 1997; present study). Therefore, fisheries' regulations should focus on the population recovery of these functionally important predatory fishes, which may be assigned to the status of 'keystone species' (see Piraino et al. 2002 for a review), or members of a 'keystone guild' (McClanahan 1995), as their simultaneous removal has the potential to profoundly alter assemblage structure and functioning of benthic rocky ecosystems (McClanahan and Sala 1997; Sala et al. 1998; Pinnegar et al. 2000).

Sea urchin fishery is practiced in many areas of the Mediterranean (see Guidetti et al. 2004, and references therein). Only P. lividus is edible, and it is thought (often based on anecdotal knowledge) that where this echinoid is heavily fished, A. lixula might compensate for the reduction in P. lividus, with no relevant effects of this fishing on the benthic assemblages. Whether or not the two species are ecologically redundant is still a matter of debate (Bulleri et al. 1999; see Boudouresque and Verlaque 2001 for a review). The present paper suggests that the two species could be differently susceptible to predation. Guidetti et al. (2004) reported that, in areas with strong $P$. lividus harvesting, A. lixula does increase, thus compensating for the reduction in P. lividus biomass. This does not imply, however, that benthic communities remain unaffected. Substantial differences between the two echinoids in their pattern of grazing (Boudouresque and Verlaque 2001), and in the rate of predation they are subject to (this study), suggest that species may be not redundant. Sea urchin fishery management should take into account that $A$. lixula populations might be less efficiently controlled by predation than $P$. lividus.

To properly support management policies of fishing activities in littoral systems, more experimental evidence is obviously needed. Studies based on direct observations similar to those reported here may contribute to a better understanding of basic ecological aspects of rocky reef ecosystems: this is fundamental for the development of ecologically-founded hypotheses that can be tested experimentally (Dayton and Sala 2001).

Acknowledgements This study forms part of P.G.'s $\mathrm{PhD}$ thesis, and was partially supported by the 'Afrodite' and 'Venere' projects funded by ICRAM and CoNISMa, respectively. Many thanks are due to E. Sala (Scripps Institution of Oceanography, USA) for his useful suggestions on underwater experimentation, to S. Bussotti (University of Lecce) for her critical revision of the manuscript, and to C. Vaglio (University of Lecce) for his invaluable help during the field work. This study was made possible thanks to the permission of S. Ciccolella (director of the Torre Guaceto MPA).

\section{References}

Andrew NL, Underwood AJ (1993) Density-dependent foraging in the sea urchin Centrostephanus rodgersii on shallow subtidal reefs in New South Wales, Australia. Mar Ecol Prog Ser 99:89-98
Boudouresque CF, Verlaque M (2001) Ecology of Paracentrotus lividus. In: Lawrence JM (ed) Edible sea urchins: biology and ecology. Elsevier, Amsterdam, pp 177-216

Bulleri F, Benedetti-Cecchi L, Cinelli F (1999) Grazing by the sea urchin Arbacia lixula $\mathrm{L}$ and Paracentrotus lividus Lmk in the Northwest Mediterranean. J Exp Mar Biol Ecol 241:81-95

Dance C, Savy S (1987) Predation on Paracentrotus lividus by Marthasterias glacialis: an in-situ experiment at Port-Cros (France Mediterranean). Posidonia Newsl 1:35-41

Dayton PK, Sala E (2001) Natural history: the sense of wonder creativity and progress in ecology. In: Gili JM, Pretus JL, Packard TT (eds) A marine science odyssey into the 21st century. Sci Mar 65 [Suppl 2]:199-206

Duffy JE, Hay ME (2001) The ecology and evolution of marine consumer-prey interactions. In: Bertness MD, Gaines SD, Hay ME (eds) Marine community ecology. Sinauer, Sunderland, Mass., pp 131-157

Duggins DO (1980) Kelp beds and sea-otters: an experimental approach. Ecology 61:447-453

Fanelli G, Piraino S, Esposito L, Boero F (1999) Opposite role of sea urchins and starfishes in marine benthic communities In: Candia Carnevali ND, Bonassoro F (eds) Echinoderm research. Balkema, Rotterdam, pp 453-457

Fischer W, Bauchot ML, Schneider M (1987) Fiches FAO d'identification des éspèces pour les besoins de la pêche Méditerranée et Mer Noire. Zone 37. II Vertebrés, vol 2. FAO, Rome, pp761-1530

Goñi R, Quetglas A, Reñones O (2001) Diet of the spiny lobster Palinurus elephas (Decapoda: Palinuridae) from the Columbretes Islands Marine Reserve (north-western Mediterranean). J Mar Biol Assoc UK 81:347-348

Guidetti P, Bianchi CN, La Mesa G, Modena M, Morri C, Sara G, Vacchi M (2002) Abundance and size structure of Thalassoma pavo (Pisces: Labridae) in the western Mediterranean Sea: variability at different spatial scales. J Mar Biol Assoc UK 82:495-500

Guidetti P, Fraschetti S, Terlizzi A, Boero F (2003) Distribution patterns of sea urchins and barrens in shallow Mediterranean rocky reefs impacted by the illegal fishery of the rock-boring mollusc Lithophaga lithophaga. Mar Biol 143:1135-1142

Guidetti P, Terlizzi A, Boero F (2004) Effects of the edible sea urchin Paracentrotus lividus fishery along the Apulian rocky coasts (SE Italy Mediterranean Sea). Fish Res 66:287-297

Hairston NG, Smith FE, Slobodkin LB (1960) Community structure population control and competition. Am Nat 94:421-425

Harmelin JG, Bachet F, Garcia F (1995) Mediterranean marine reserves: fish indices as tests of protection efficiency. PSZN: Mar Ecol 16:233-250

McClanahan TR (1995) Fish predators and scavengers of the sea urchin Echinometra mathaei in Kenyan coral-reef marine parks. Environ Biol Fishes 43:187-193

McClanahan TR (1999) Predation and the control of the sea urchin Echinometra viridis and fleshy algae in the patch reefs of Glovers reef Belize. Ecosystems 2:511-523

McClanahan TR, Muthiga NA (1989) Patterns of predation on a sea urchin, Echinometra mathaei (de Blainville), on Kenyan coral reefs. J Exp Mar Biol Ecol 126:77-94

McClanahan TR, Sala E (1997) A Mediterranean rocky-bottom ecosystem fisheries model. Ecol Model 104:145-164

McClanahan TR, Shafir SH (1990) Causes and consequences of sea urchin abundance and diversity in Kenyan coral reef lagoons. Oecologia 83:362-370

Paine RT (1980) Food webs linkage interaction strength and community infrastructure. J Anim Ecol 49:667-685

Pinnegar JK, Polunin NVC, Francour P, Badalamenti F, Chemello R, Harmelin-Vivien ML, Hereu B, Milazzo M, Zabala M, D'Anna G, Pipitone C (2000) Trophic cascades in benthic marine ecosystems: lessons for fisheries and protected-area management. Environ Conserv 27:179-200

Piraino S, Fanelli G, Boero F (2002) Variability in species' roles in marine communities: change of paradigms for conservation priorities. Mar Biol 140:1067-1074 
Power ME (1992) Top-down and bottom-up forces in food webs: do plants have primacy? Ecology 73:733-746

Sala E (1997) Fish predators and scavengers of the sea urchin Paracentrotus lividus in protected areas of the north-western Mediterranean Sea. Mar Biol 129:531-539

Sala E, Zabala M (1996) Fish predation and the structure of the sea urchin Paracentrotus lividus populations in the NW Mediterranean. Mar Ecol Prog Ser 140:71-81

Sala E, Boudouresque CF, Harmelin-Vivien M (1998) Fishing trophic cascades and the structure of algal assemblages: evaluation of an old but untested paradigm. Oikos 82:425-439

Savy S (1987a) Les predateurs de Paracentrotus lividus (Echinodermata) In: Boudouresque CF (ed) Colloque international sur Paracentrotus lividus et les oursins comestibles. GIS Posidonie, Marseille, pp 413-423

Savy S (1987b) Activity pattern of the sea-star, Marthasterias glacialis, in Port-Cros Bay (France, Mediterranean coast). PSZN Mar Ecol 8:97-106
Scheibling RE (1996) The role of predation in regulating sea urchin populations in eastern Canada. Oceanol Acta 19:421-430

Shepherd SA, Boudouresque CF (1979) A preliminary note on the movement of the sea urchin Paracentrotus lividus. Trav Sci Parc Nat Port-Cros 5:155-158

Tegner MJ, Dayton PK (1981) Population structure recruitment and mortality of two sea urchins (Strongylocentrotus franciscanus and S. purpuratus) in kelp forest. Mar Ecol Prog Ser 5:255-268

Tegner MJ, Dayton PK, Edwards PB, Riser KL (1995) Sea urchin cavitation of giant kelp (Macrocystis pyrifera C Agardh) holdfasts and its effects on kelp mortality across a large California forest. J Exp Mar Biol Ecol 191:83-99

Verling E, Crook AC, Bernes KA, Harrison SSC (2003) Structural dynamics of a sea-star population. J Mar Biol Assoc UK 83:583-592

Witman JD, Dayton PK (2001) Rocky subtidal communities In: Bertness MD, Gaines SD, Hay ME (eds) Marine community ecology. Sinauer, Sunderland, Mass., pp 339-366 